\title{
Palliative treatment of Kaposi sarcoma with radiotherapy: a single center experience
}

\author{
Gonca Altinisik Inan ${ }^{1}$, Ipek Pinar Aral ${ }^{2}$, Suheyla Aytac Arslan', Yilmaz Tezcan ${ }^{1}$ \\ 'Department of Radiation Oncology, Ankara City Hospital, Ankara, Turkey \\ ${ }^{2}$ Department of Radiation Oncology, Nevsehir Public Hospital, Nevsehir, Turkey
}

Received: October 26, 2020

Revised: January 28, 2021

Accepted: February 2, 2021

\section{Correspondence:}

Gonca Altinisik Inan

Department of Radiation Oncology,

Ankara City Hospital, Cankaya 06400,

Ankara, Turkey

Tel: +90-5079976769

E-mail: goncaaltinisikinan@gmail.com ORCID:

https://orcid.org/0000-0002-7385-3480
Purpose: The aim of this study is to evaluate the treatment responses of Kaposi sarcoma patients treated with radiotherapy (RT).

Materials and Methods: The data of 18 patients (40 different regions) who were treated for Kaposi sarcoma in Department of the Radiation Oncology, Ankara City Hospital, Turkey between March 23, 2010 to February 13, 2018 were evaluated retrospectively. The primary endpoint of the study was the clinical-subjective response after RT, and the secondary endpoint was the visual response assessment after RT.

Results: In evaluating the patients' reported response of the lesions: 25 (62.5\%) of complete response (CR), 12 (30\%) of partial response (PR), and stable response was seen in 3 patients (7.5\%). Patient reported response after RT was significantly higher in male sex $(p=0.002$; odds ratio $[O R]=13.8,95 \%$ confidence interval [Cl], 2.7-70.0). Physician reported response rates were available for 28 lesions and CR was detected in 12 lesions (30\%); PR was observed in 16 (40\%). The relationship between physician reported outcome and RT techniques (electron, bolus, or water bolus) is close to the limit of statically significance $(p=0.052)$. Fewer lesions disappeared in patients with photon preference than electrons ( $p=0.036 ; O R=0.093 ; 95 \% \mathrm{Cl}, 0.009-0.950$ ). Patients' reported complete response rates were significantly higher in the 20 Gy per 5 fractions treatment arm $(p=0.042 ; O R=1.75 ; 95 \% \mathrm{Cl}$, 1.1-2.7).

Conclusion: RT is an effective local treatment with high response rates in the treatment of Kaposi sarcoma. The subjective-clinical response rate was higher in male sex and the visual response was higher in the 20 Gy per 5 fractions arm. Additional studies are needed to standardize RT dose and techniques.

Keywords: Kaposi sarcoma, Radiotherapy, Palliative therapy

\section{Introduction}

Kaposi sarcoma (KS) is an angio-proliferative malignant neoplasm of lymphatic endothelial origin which was described by Moritz Kaposi in $1872[1,2]$. Although there are four main subtypes, classic Kaposi sarcoma (CKS) is the most common in the Mediterranean region. Other subtypes are endemic (African), epidemic (human immunodeficiency virus [HIV]-related) and iatrogenic KS. The male dominance is observed in CKS, most located in the lower extremity, and has a better prognosis than other types $[3,4]$. Radiotherapy (RT) is an effective treatment in all subtypes [5].

$\mathrm{RT}$ is an effective local treatment which is frequently preferred in palliative treatment of KS [1]. KS is radiosensitive and response rates to treatment are reported as high as 70\%-95\% [6]. Akmansu et al. [1] reported that complete response rates were $86.7 \%$ at 6 th months and $93.3 \%$ at 12 th months control. In the study of Kandaz

Copyright (C) 2021 The Korean Society for Radiation Oncology

This is an Open Access article distributed under the terms of the Creative Commons Attribution Non-Commercial License (http://creativecommons.org/licenses/by-nc/4.0/) which permits unrestricted non-commercial use, distribution, and reproduction in any medium, provided the original work is properly cited. 
et al. [7], 89\%-91\% CR was obtained. However, there is no accepted standard practice in terms of RT dose and technique. The electrons or low energy photon is generally used in the treatments and 8 Gy per 1 fraction, 30 Gy per 10-15 fractions, 20 Gy per 4-5 fractions doses are frequently preferred $[1,3,4]$.

In this study, we aimed to investigate the treatment response and visual response of the lesion in patients with KS who underwent extremity RT for palliative purposes.

\section{Materials and Methods}

The data of 18 patients (40 different regions) who were treated with KS in Ankara City Hospital between March 23, 2010 to February 13, 2018 were evaluated retrospectively. The patient interview information, patient files, and electronic system data were used for the study. The patients' demographic status, initial complaint, RT dose administered, field information, treatment responses and final status were noted. The primary endpoint of the study was to assess whether patients had adequate palliation (patients' reported outcomes after RT) on their complaints. Clinicians were asked to patients at first control after RT "If the first complaints before RT are 10, how many do you consider now?" The answers given by the patients were noted. In addition, visual response evaluation was performed at the post-treatment 30-45 days controls and visual analysis of the final lesion (physician reported outcomes after RT) was determined as the secondary endpoint. Adult patients with KS who underwent RT in our clinic and whose information was fully available were included in the study. Patients with missing files and follow-up information were excluded from the study. The study was conducted in accordance with the Helsinki Declaration, which was approved by the Ethics Committee of Ankara City Hospital in November 2019 (No. E1/056/2019). The informed consent was waived.

\section{RT Technique}

The treatments were applied by using synergy device with electron and 6-MV photon. RT technique and energy preference were dependent to the size of the lesion and the choice of treating physician. In electron treatments, the RT area was determined between 5-15 cm according to lesion size and $0.5-1 \mathrm{~cm}$ plexiglass tissue equivalent material was used as bolus. In accordance with the literature $[1,4,7], 11.5-2 \mathrm{~cm}$ margin was determined to each lesion. The $6 \mathrm{MV}$ energy was used in photon treatments. The extremity was placed into the water support to cover the lesion and irradiation was performed from the opposite lateral fields. RT dose and technical details are summarized in Tables 1 and 2 .
Table 1. Patient demographics and treatment details

\begin{tabular}{|c|c|}
\hline Characteristic & Number of patients (\%) \\
\hline \multicolumn{2}{|l|}{ Sex } \\
\hline Male & $11(61.1)$ \\
\hline Female & 7 (38.9) \\
\hline \multicolumn{2}{|l|}{ RT site } \\
\hline Left lower distal extremity & $15(37.5)$ \\
\hline Right lower distal extremity & $14(35)$ \\
\hline Left hand & $4(10)$ \\
\hline Right hand & $4(10)$ \\
\hline Left upper distal extremity & $3(7.5)$ \\
\hline \multicolumn{2}{|l|}{ Complaint } \\
\hline Edema & $20(50)$ \\
\hline Pain & $16(40)$ \\
\hline Pruritis & $6(15)$ \\
\hline Bleeding & $4(10)$ \\
\hline \multicolumn{2}{|l|}{ Number of RT site } \\
\hline One & $3(16.6)$ \\
\hline Two & $10(66.6)$ \\
\hline Three & $1(5.5)$ \\
\hline Five & $2(11.1)$ \\
\hline \multicolumn{2}{|l|}{ RT clinical response } \\
\hline $\mathrm{CR}$ & $24(60)$ \\
\hline PR & $13(32.5)$ \\
\hline Stable & $3(7.5)$ \\
\hline \multicolumn{2}{|l|}{ RT visual response } \\
\hline $\mathrm{CR}$ & $13(32.5)$ \\
\hline PR & $16(40)$ \\
\hline Not evaluated & $11(27.5)$ \\
\hline \multicolumn{2}{|l|}{ RT doses } \\
\hline $6 \mathrm{~Gy} / 1 \mathrm{fx}$ & $1(2.6)$ \\
\hline $7 \mathrm{~Gy} / 1 \mathrm{fx}$ & $2(5.1)$ \\
\hline $8 \mathrm{~Gy} / 1 \mathrm{fx}$ & $19(46.2)$ \\
\hline $20 \mathrm{~Gy} / 5 \mathrm{fx}$ & $5(12.8)$ \\
\hline $27 \mathrm{~Gy} / 9 \mathrm{fx}$ & $2(5.1)$ \\
\hline $30 \mathrm{~Gy} / 10 \mathrm{fx}$ & $9(23.1)$ \\
\hline $32.5 \mathrm{~Gy} / 9 \mathrm{fx}$ & $2(5.1)$ \\
\hline \multicolumn{2}{|l|}{ RT techniques } \\
\hline Water bolus & $28(65.7)$ \\
\hline Plexiglass & $2(7.5)$ \\
\hline Electron & $10(2.5)$ \\
\hline \multicolumn{2}{|l|}{ Last status } \\
\hline Ex & $5(27.8)$ \\
\hline Alive & $13(72.2)$ \\
\hline \multicolumn{2}{|l|}{ RT } \\
\hline Photons & 30 (75) \\
\hline Electrons & $10(25)$ \\
\hline
\end{tabular}

$\mathrm{RT}$, radiotherapy; $\mathrm{CR}$, complete response; $\mathrm{PR}$, partial response. 
Table 2. Patients' details

\begin{tabular}{|c|c|c|c|c|c|c|c|}
\hline Case no. & KS type & Age at the time of RT (yr) & Sex & RT site & Complaint (most obvious) & Clinical response & Visual response \\
\hline \multirow[t]{2}{*}{1} & Classic & 74 & Female & RLDE & Pain & PR & NE \\
\hline & & & & LLDE & Pain & PR & NE \\
\hline \multirow[t]{2}{*}{2} & Classic & 57 & Female & RLDE & Bleeding & PR & PR \\
\hline & & & & LLDE & Bleeding & PR & PR \\
\hline \multirow[t]{2}{*}{3} & Classic & 82 & Male & RLDE & Edema & PR & NE \\
\hline & & & & LLDE & Edema & PR & NE \\
\hline \multirow[t]{2}{*}{4} & Classic & 78 & Male & RLDE & Pain & $\mathrm{CR}$ & $\mathrm{CR}$ \\
\hline & & & & LLDE & Pain & $\mathrm{CR}$ & $\mathrm{CR}$ \\
\hline 5 & Classic & 80 & Female & LLDE & Pain & $\mathrm{CR}$ & $\mathrm{CR}$ \\
\hline \multirow[t]{2}{*}{6} & Classic & 74 & Female & RLDE & Pruritis & $\mathrm{CR}$ & $\mathrm{CR}$ \\
\hline & & & & LLDE & Pruritis & $\mathrm{CR}$ & $\mathrm{CR}$ \\
\hline 7 & Classic & 67 & Female & LUDE & Pain & PR & PR \\
\hline 8 & Classic & 84 & Female & RLDE & Edema & Stable & PR \\
\hline \multirow[t]{5}{*}{9} & Classic & 67 & Male & LUDE & Edema & PR & NE \\
\hline & & & & LLDE & Edema & $\mathrm{CR}$ & $\mathrm{CR}$ \\
\hline & & & & $\mathrm{RH}$ & Edema & Stable & PR \\
\hline & & & & RLDE & Edema & $\mathrm{CR}$ & PR \\
\hline & & & & $\mathrm{LH}$ & Edema & $\mathrm{CR}$ & PR \\
\hline \multirow[t]{2}{*}{10} & Classic & 69 & Male & RLDE & Bleeding & $C R$ & $\mathrm{CR}$ \\
\hline & & & & LLDE & Bleeding & $\mathrm{CR}$ & CR \\
\hline \multirow[t]{2}{*}{11} & Classic & 78 & Male & $\mathrm{LH}$ & Pain & $\mathrm{CR}$ & $\mathrm{CR}$ \\
\hline & & & & LLDE & Pain & PR & PR \\
\hline \multirow[t]{2}{*}{12} & Classic & 79 & Male & RLDE & Pruritis & $\mathrm{CR}$ & NE \\
\hline & & & & LLDE & Pruritis & $\mathrm{CR}$ & PR \\
\hline \multirow[t]{3}{*}{13} & Classic & 71 & Female & $\mathrm{RH}$ & Edema & PR & $N E$ \\
\hline & & & & $\mathrm{LH}$ & Edema & Stable & PR \\
\hline & & & & RLDE & Edema & PR & PR \\
\hline \multirow[t]{2}{*}{14} & Classic & 78 & Male & RLDE & Edema & $\mathrm{CR}$ & NE \\
\hline & & & & LLDE & Edema & $\mathrm{CR}$ & PR \\
\hline \multirow[t]{5}{*}{15} & Classic & 80 & Male & LUDE & Edema & $\mathrm{CR}$ & $\mathrm{NE}$ \\
\hline & & & & LLDE & Edema & $\mathrm{CR}$ & $\mathrm{CR}$ \\
\hline & & & & RLDE & Edema & $\mathrm{CR}$ & $\mathrm{CR}$ \\
\hline & & & & $\mathrm{RH}$ & Edema & $\mathrm{CR}$ & $\mathrm{CR}$ \\
\hline & & & & $\mathrm{RH}$ & Edema & $\mathrm{CR}$ & $\mathrm{CR}$ \\
\hline \multirow[t]{2}{*}{16} & Classic & 81 & Male & RLDE & Pain & $\mathrm{CR}$ & $N E$ \\
\hline & & & & LLDE & Pain & $\mathrm{CR}$ & NE \\
\hline \multirow[t]{2}{*}{17} & Classic & 67 & Male & LLDE & Edema & PR & PR \\
\hline & & & & $\mathrm{LH}$ & Edema & PR & PR \\
\hline \multirow[t]{2}{*}{18} & Classic & 52 & Male & RLDE & Pruritis & $\mathrm{CR}$ & PR \\
\hline & & & & LLDE & Pruritis & $\mathrm{CR}$ & PR \\
\hline
\end{tabular}

KS, Kaposi sarcoma; RT, radiotherapy; RLDE, right lower distal extremity, LLDE, left lower distal extremity; LUDE, left upper distal extremity; RH, right hand; $L H$, left hand; $N E$, not evaluated; $C R$, complete response; $P R$, partial response.

\section{Statistics}

The SPSS version 26 (IBM, Armonk, NY, USA) were used. The suitability of the variables to the normal distribution was evaluated by visual-analysis methods and non-parametric tests were used since it was observed that they did not fit the normal distribution. Chi- square and Fisher exact tests were used to determine the demographic characteristics of the patients. The Cox regression test was used in multivariate analysis. Odds ratio and 95\% confidence interval values noted if the results were significantly difference. Mann-Whitney $U$ test was used for independent statistical analysis 
of two groups and Kruskal-Wallis test was used for three and more independent groups. Statistically significant limit was accepted as less than 0.05 .

\section{Results}

The 18 patients (40 different regions) that RT was applied between March 23, 2010 to February 13, 2018 were evaluated. The median age of the patients was 76 years (range, 52 to 84 years). Eleven $(61.1 \%)$ of the patients were male and $7(38.9 \%)$ were women. RT was applied to left lower distal extremity in 15 (37.5\%) and to right lower distal extremity in 14 (35\%); 4 (10\%) in left hand, 4 $(10 \%)$ in right hand, $3(7.5 \%)$ located in the upper left distal extremity. Clinicians asked to patients about their most disturbing complaints and minimum one complaint maximum three complaints were noted. The most common RT presentation sign was edema (50\%) and pain (40\%). The median RT area of the patients was 2 (range, 1 to 5 ).

There were two lesions that had been treated with RT at the outer center and had recurrent lesions at the same site and $6 \mathrm{~Gy}$ per 1 fraction and 7 Gy per 1 fraction doses were given. The most common treatment protocol was 8 Gy per 1 fraction and was administered to $18(46.2 \%)$ patients. The electron was applied to 10 (25\%) and photon was applied to 30 (75\%) of the lesions. The median follow-up period was 36 months (range, 3 to 116 months).

\section{Clinical-subjective response analysis after RT}

In the post-RT controls (patients' reported response after RT-when the patient's complaint was asked) no patient showed progression. The complete response (CR; defined as $90 \%$ or more reduction in complaints) $[1,4,8]$ was observed in $24(60 \%)$ of the 40 lesions in total. Partial response (PR; although there is a decrease in complaints, the complaints continue) $[1,4,8]$ was observed in 13 $(32.5 \%)$ patients and stable response was seen in $3(7.5 \%)$ patients.

The patients were analyzed as those aged under 65 years versus over 65 years. The relationship between age and patients' reported outcome was not statistically significant ( $p=0.59$ ), but only four patients were younger than 65 years. There was no significant relationship between the area receiving $\mathrm{RT}$ and clinical outcomes $(\mathrm{p}=$
0.14). In addition, initial complaint ( $p=0.29$ ), RT techniques (electron, bolus, or water bolus) ( $p=0.62$ ), electron or photon preference $(p=0.35)$, RT total dose $(p=0.85)$, RT fraction dose $(p=$ $0.13)$, RT site $(p=0.07)$, and number of RT site $(p=0.61)$ did not significantly affect the results. The difference between patient reported response and the three most used doses of 8 Gy per 1 fractions versus 20 Gy per 5 fractions versus 30 Gy per 10 fractions was not significant ( $p=0.52$ ). In the result of the Cox regression analysis of the relationship between RT clinical response and sex, CR was found to be significantly higher in male sex $(p=0.004$; odds ratio $[\mathrm{OR}]=12.5 ;$ 95\% confidence interval $[\mathrm{Cl}], 2.5-70)$ (Table 3 ).

\section{Physician reported response analysis after RT}

The notes of the clinician's visual evaluation of the lesions were present in the file for 29 lesions and not for the 11 lesions. According to the clinician examination, CR-disappearance in 13 (32.5\%) lesions; in 16 (40\%), lesion regression was observed.

The relationship between age and visual outcome was not statistically significant ( $p=0.17$ ), but only four patients were younger than 65 years. There was also no significant relationship between the RT area and visual results ( $p=0.64)$, the initial complaint ( $p=0.77)$, sex $(p=0.21)$, RT fraction doses ( $p=0.17)$, RT site ( $p=0.063)$, and number of RT site ( $p=0.72)$.

The relationship between the visual results obtained by the clinician at 1 month after RT and the RT techniques (electron, bolus, or water bolus) is close to the limit of statically significance ( $p=$ 0.056). The difference may become significant if the number of patients increases (Table 4).

The preferred energy was the electron vs photon, which significantly affected the results of the physicians' reported responses. According to the Cox regression analysis, fewer lesions disappeared in patients with photon preference $(p=0.036 ; 0 R=0.093 ; 95 \%$ Cl, 0.009-0.950) (Table 4).

The difference between the three most used doses and the visual results was significant in favor of 20 Gy per 5 fractions, with a higher rate of $C R$ in the 20 Gy receiving arm ( $p=0.042 ; 0 R=$ 1.75; 95\% Cl, 1.1-2.7) (Table 4).

Table 3. Sex and clinic response analysis

\begin{tabular}{|c|c|c|c|c|c|}
\hline & \multicolumn{3}{|c|}{ RT/patients' reported response (for each lesions) } & \multirow{2}{*}{ p-value } & \multirow{2}{*}{ OR $(95 \% \mathrm{Cl})$} \\
\hline & CR & PR & Stable & & \\
\hline Sex & & & & 0.004 & $12.5(2.5-70.0)$ \\
\hline Female & $3(27.2)$ & $6(54.5)$ & $2(18.1)$ & & \\
\hline Male & 22 (75.8) & $6(20.6)$ & $1(3.4)$ & & \\
\hline
\end{tabular}

Values are presented as number (\%).

$\mathrm{RT}$, radiotherapy; $\mathrm{CR}$, complete response; $\mathrm{PR}$, partial response; $\mathrm{OR}$, odds ratio; $\mathrm{Cl}$, confidence interval. 
Table 4. RT technique, energy, schemas, and visual response analysis

\begin{tabular}{|c|c|c|c|c|}
\hline & \multicolumn{2}{|c|}{ RT visual response (for each lesions) } & \multirow{2}{*}{$p$-value } & \multirow{2}{*}{ OR $(95 \% \mathrm{Cl})$} \\
\hline & $\mathrm{CR}$ & PR & & \\
\hline RT technique & & & 0.056 & - \\
\hline Water nolus & $6(31.5)$ & $13(68.5)$ & & \\
\hline Bolus (plexiglass) & $2(100)$ & $0(0)$ & & \\
\hline Electron-No bolus & 5 (83.3) & $1(16.7)$ & & \\
\hline RT energy & & & 0.036 & $0.093(0.009-0.950)$ \\
\hline Electrons & 5 (83.3) & 1 (16.7) & & \\
\hline Photons & $7(31.8)$ & $15(68.2)$ & & \\
\hline RT schemas & & & 0.050 & $1.750(1.100-2.700)$ \\
\hline 30 Gy per $10 \mathrm{fx}$ & $0(0)$ & $6(100)$ & & \\
\hline 20 Gy per $5 \mathrm{fx}$ & $3(75.0)$ & $1(25.0)$ & & \\
\hline 8 Gy per $1 \mathrm{fx}$ & $7(46.7)$ & 8 (53.3) & & \\
\hline
\end{tabular}

Values are presented as number (\%).

$\mathrm{RT}$, radiotherapy; $\mathrm{CR}$, complete response; $\mathrm{PR}$, partial response; $\mathrm{OR}$, odds ratio; $\mathrm{Cl}$, confidence interval.

\section{Discussion and Conclusion}

In the current study, the results of RT applied to 40 lesions of 18 patients were presented. Patient reported CR was observed in 24 (60\%) of the lesions where RT was applied. PR was observed in 13 (32.5\%) patients and stable response was seen in $3(7.5 \%)$ patients. Subjective regression in complaints was significantly higher in male sex. The clinician's visual evaluation of the lesions revealed CR-disappearance in 13 (32.5\%) lesions; in 16 (40\%), lesion regression was observed. Clinician-noted CR rates were significantly higher in patients with electron preferred and using 20 Gy per 5 fractions schema.

KS is more frequently observed in men $[9,10]$. The current data are available on the relationship of high incidence with androgen receptors $[11,12]$. Despite the high incidence in men, limited data are available on the gender-treatment response. Phipps et al. [13] conducted a study on gender in their study on 197 epidemic KS in 2010. According to the study [13], significantly lower CD4 T cells were reported in women compared to men. In females, lesions were more frequently located on the face and hard palate, whereas in males more in lower extremity. The clinical improvementwas lower in women in multivariate analysis (hazard ratio $[H R]=0.52 ; 95 \%$ $\mathrm{Cl}, 0.31-088 ; \mathrm{p}=0.01$ ) [13]. In many pioneering RT studies on this subject, the relationship between gender and RT-results has not been analyzed $[1,4,8]$. In our study, the patient reported response rate in men was significantly higher than in women.

The main indications for palliative RT are bleeding, pain, pruritus, and edema [14]. KS is a radiosensitive tumor and there is a high response rate in the literature $[1,6]$ for palliative purposes [6]. In a study by Tsao et al. [15], the clinical response rate was 87\% (CR = $30 \%$, PR $=57 \%$ ). In the study of Yildız et al. [8], the clinical re- sponse rate was 93\%. In a study of 18 HIV-related KS patients by Donato et al. [5], 83.3\% CR was obtained in patients. In the current study, 92.5\% (CR + PR) subjective response was consistent with the literature. Palliation was achieved in more than $90 \%$ of our patients.

In this study, the patient's complaint (except pain and itching bleeding) was evaluated by the clinician in the appearance of pigmented lesion. There are few studies evaluating the pigmented lesion by the clinician. In the study of Stelzer and Griffin [16], this rate is around 50\%. In the study of Harrison et al. [17], loss of pigmented lesion was reported as high as 78.8\%. In our study, CR-disappearance in 13 (32.5\%) lesions; in 16 (40\%), lesion partial regression was observed.

KS often presents as a multicentric lesion [6]. In our study, the median RT area of the patients was 1 (range, 1 to 5) and all the RT areas are on extremity localization. Extremities are irregular surfaces and bolus materials have been used for a long time to ensure homogeneous dose distribution [18]. In our study, water bolus, tissue equivalent $0.5-1 \mathrm{~cm}$ thick bolus material, and electron irradiation without bolus were performed. CR was observed in 2 (100\%) patients using tissue equivalent-plexiglass material. While $83.3 \%$ $\mathrm{CR}$ was observed in electron without bolus application, this ratio decreased to $31.5 \%$ in water bolus ( $p=0.056$ ). The difference is close to statistically significant. Statically significant results can be obtained in studies with more patients and can be seen a lower visual response in treatment with water bolus.

In the literature $[1,5,8]$, different results were obtained in the main studies evaluating the relationship between dose-response and overall response rates were high in all arms. Harrison et al. [17] were compared 16 Gy per 4 fractions versus 8 Gy per 1 fraction doses prospectively; there was no significant difference between 
the two doses in terms of response. In the study of Stelzer et al. [16], 8 Gy per 1 fraction versus 20 Gy per 10 fractions versus 40 Gy per 20 fractions were compared, and a significantly higher CR was observed in fractionated treatments. In a study by Sing et al. [19], 24 Gy per 12 fractions and 20 Gy per 5 fractions were prospectively randomized and no significant difference was observed in terms of treatment response or side effects. In the study of Oysul et al. [20] evaluating 18 CKS patients, higher CR was reported at doses of 20 Gy and above. In the study of Kandaz et al. [7], CR was $91.6 \%$ in treatments over $20 \mathrm{~Gy}$, while this value was reported as $89.6 \%$ in the 8 Gy per 1 fraction arm. In summary, although fractional therapies with a dose of 20 Gy or higher are associated with higher CR, overall treatment responses are high for all treatment arms. In our study, the three most used doses were 8 Gy per 1 fraction versus 20 Gy per 5 fractions versus 30 Gy per 10 fractions, and the difference between clinical responses was not significant ( $p=0.52$ ). However, the difference between the three most used doses and the visual results was significant in favor of 20 Gy per 5 fractions, with a higher rate of $C R$ in the 20 Gy receiving arm $(p=0.042 ; 0 R$ $=1.75 ; 95 \% \mathrm{Cl}, 1.1-2.7)$.

There are some weaknesses of the study. First of all, the study is retrospective and single-centered. Patients' previous surgical or systemic treatment details and responses could not be analyzed because they were not noted. In our study, extremity irradiation was evaluated, and facial or oral irradiation was not performed in our clinic. There are no acute and late side effect data for RT. However, in our study, the lesion analysis of the clinician was also evaluated in addition to palliation of the patient's presenting complaint. In addition, different RT techniques were analyzed.

In conclusion, RT is an effective local treatment and high response rates in the treatment of KS. The subjective response rate was higher in male sex, whereas visual response was higher in electron treatments and 20 Gy per 5 fractions scheme. Additional studies are needed to make RT dose and techniques standard.

\section{Conflict of Interest}

No potential conflict of interest relevant to this article was reported.

\section{References}

1. Akmansu M, Goksel F, Erpolat OP, Unsal D, Karahacioglu E, Bora H. The palliative radiotherapy of classic Kaposi's sarcoma of foot region: retrospective evaluation. Int J Hematol Oncol 2014;29: 147-52.

2. Szajerka T, Jablecki J. Kaposi's sarcoma revisited. AIDS Rev
2007:9:230-6.

3. Ramirez K, Zavala J, Moran D, Hernandez D, Jimenez A. Classic Kaposi's sarcoma: complete response to radiation therapy: a case report. J Med Case Rep 2016;10:322.

4. Teke $F_{1}$ Akkurt Z. Evaluation of 14 patients performed radiotherapy due to Kaposi sarcoma. Dicle Med J 2015;42:326-30.

5. Donato V, Guarnaccia R, Dognini J, et al. Radiation therapy in the treatment of HIV-related Kaposi's sarcoma. Anticancer Res 2013; 33:2153-7.

6. Becker G, Bottke D. Radiotherapy in the management of Kaposi's sarcoma. Onkologie 2006;29:329-33.

7. Kandaz M, Bahat Z, Guler OC, Canyilmaz E, Melikoglu M, Yoney A. Radiotherapy in the management of classic Kaposi's sarcoma: a single institution experience from Northeast Turkey. Dermatol Ther 2018;31:e12605.

8. Yildiz F, Ozyar E, Uzal D, Sahin S, Atahan IL. Kaposi's sarcoma: the efficacy of a single fraction of 800 cGy. Dermatology 1997;195: 142-4.

9. Fatahzadeh M. Kaposi sarcoma: review and medical management update. Oral Surg Oral Med Oral Pathol Oral Radiol 2012;113:2-16.

10. Cetin B, Aktas B, Bal O, et al. Classic Kaposi's sarcoma: a review of 156 cases. Dermatologica Sinica 2018;36:185-9.

11. Zhang T, Lin H, Minhas V, Zhu W, Wood C, He N. Prevalence and correlates of Kaposi's sarcoma-associated herpesvirus infection in a sample of men who have sex with men in Eastern China. Epidemiol Infect 2013;141:1823-30.

12. Wang $X, Z$ Zou Z, Deng $Z$, et al. Male hormones activate EphA2 to facilitate Kaposi's sarcoma-associated herpesvirus infection: implications for gender disparity in Kaposi's sarcoma. PLoS Pathog 2017;13:e1006580.

13. Phipps W, Ssewankambo F, Nguyen $H_{1}$ et al. Gender differences in clinical presentation and outcomes of epidemic Kaposi sarcoma in Uganda. PLoS One 2010;5:e13936.

14. Radu O, Pantanowitz L. Kaposi sarcoma. Arch Pathol Lab Med 2013;137:289-94.

15. Tsao MN, Sinclair $E_{1}$ Assaad D, Fialkov J, Antonyshyn O, Barnes E. Radiation therapy for the treatment of skin Kaposi sarcoma. Ann Palliat Med 2016;5:298-302.

16. Stelzer KJ, Griffin TW. A randomized prospective trial of radiation therapy for AIDS-associated Kaposi's sarcoma. Int J Radiat Oncol Biol Phys 1993;27:1057-61.

17. Harrison M, Harrington KJ, Tomlinson DR, Stewart JS. Response and cosmetic outcome of two fractionation regimens for AIDS-related Kaposi's sarcoma. Radiother Oncol 1998;46:23-8.

18. Saw CB, Wen BC, Anderson K, Pennington E, Hussey DH. Dosimetric considerations of water-based bolus for irradiation of extremities. Med Dosim 1998;23:292-5. 
19. Singh NB, Lakier RH, Donde B. Hypofractionated radiation therapy in the treatment of epidemic Kaposi sarcoma: a prospective randomized trial. Radiother Oncol 2008;88:211-6.
20. Oysul K, Beyzadeoglu M, Surenkok S, Ozyigit G, Dirican B. A dose-response analysis for classical Kaposi's sarcoma management by radiotherapy. Saudi Med J 2008;29:837-40. 